\title{
SOFTWARE SIBELIUS SEBAGAI ALTERNATIF PENULISAN NOTASI MUSIK DI ERA MILLENIAL
}

\section{SIBELIUS SOFTWARE AS AN ALTERNATIVE OF NOTATION MUSIC WRITING IN THE MILLENIAL ERA}

\author{
Fajry Sub'haan Syah Sinaga'; Esy Maestro²; Marzam³ ${ }^{3}$ Yensharti ${ }^{4}$ \\ Jurusan Sendratasik, Fakultas Bahasa dan Seni, Universitas Negeri Padang \\ ${ }^{(*)} \bowtie$ (e-mail) fajry.sinaga@fbs.unp.ac.id ${ }^{1}$; esymaestro@gmail.com²; marzam1960@fbs.unp.ac.id²; \\ estigayens@gmail.com
}

\begin{abstract}
Abstrak
Penelitian ini bertujuan untuk memberikan pengetahuan dan keterampilan tentang penulisan notasi musik menggunakan software sibelius yang dapat digunakan sebagai alternatif dalam mengembangkan bahan ajar pada mata pelajaran Seni Budaya pada tingkat Sekolah Menengah. Pendekatan yang digunakan adalah artistik "Art Practice Based Research" dengan metode deskripsi analitis dan beberapa pelatihan kepada guru Seni Budaya di Kabupaten Solok menggunakan modul yang telah dibuat dan dipelajari kurang lebih tiga pertemuan. Hasil penelitian menunjukkan bahwa penggunaan software sibelius sangat efektif untuk menuliskan notasi musik dan mengembangkan bahan ajar berupa aransemen lagu sederhana dalam format ansambel alat musik sekolah seperti pianika, rekorder, perkusi, dan sebagainya.
\end{abstract}

Kata kunci: sibelius, aransemen, notasi, millenial

\begin{abstract}
This study aims to provide knowledge and skills about writing music notation using sibelius software which can be used as an alternative in developing teaching materials on Seni Budaya subject at the Middle School level. The approach used is artistic "Art Practice Based Research" with analytical description methods and some training for Art and Culture teachers in Solok Regency using modules that have been created and studied in approximately three meetings. The results showed that the use of sibelius software was very effective for writing music notation and developing teaching materials in the form of simple song arrangements in the format of school musical instruments such as pianika, recorders, percussion, and etc.
\end{abstract}

Keywords: sibelius, arrangement, notation, millenial 


\section{Pendahuluan}

Teknologi Informasi yang berkembang sangat pesat, mempermudah guru maupun siswa dalam melakukan proses pembelajaran. Penerapan teknologi dan informasi menjadi suatu hal yang wajib dilakukan dalam dunia pendidikan. Pasalnya, hampir setiap institusi pendidikan telah menggunakan teknologi sebagai penunjang setiap kegiatan yang sangat erat kaitannya dengan pembelajaran di era millenial.

Berdasarkan data (S, 2016) generasi millenial dapat dikategorikan generasi yang lahir dalam rentan waktu awal tahun 1980 hingga tahun 2000. Karakteristik yang dimiliki oleh generasi millenial, yaitu (1) Millenial kurang suka membaca secara konvensional, bagi generasi ini tulisan dirasa memusingkan dan membosankan. Generasi Millenial dapat dikatakan lebih tertarik melihat gambar, terlebih jika gambarnya menarik dan berwarna; (2) Millenial lebih mengerti teknologi dibanding orang tua mereka. Generasi millennial adalah generasi yang sangat modern, lebih dari pada orang tua mereka, sehingga tak jarang merekalah yang mengajarkan teknologi pada kalangan orangtua.

Seni Budaya dan Keterampilan (SbK) adalah salah satu bidang mata pelajaran yang menggunakan teknologi digital dalam pelaksanaannya. Dilansir tulisan kompasiana perbedaan generasi millenial dengan sebelumnnya.

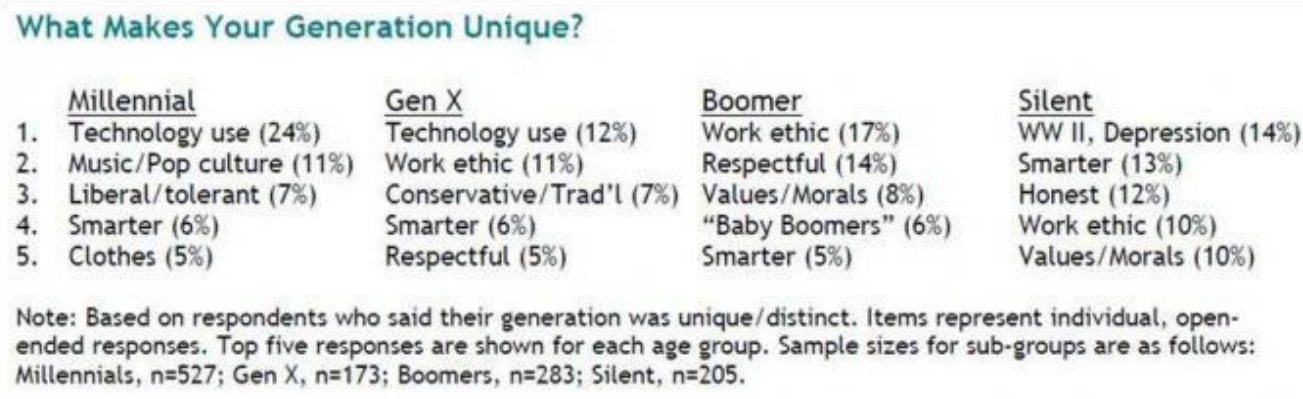

Note: Based on respondents who said their generation was unique/distinct. Items represent individual, openended responses. Top five responses are shown for each age group. Sample sizes for sub-groups are as follows: Millennials, $n=527$; Gen $X, n=173$; Boomers, $n=283$; Silent, $n=205$.

Gambar 1. Perbedaan Generasi Milenial dengan Generasi Sebelumnya Sumber: Kompasiana

Berdasarkan gambar diatas, membuktikan bahwa generasi millenial sangat erat kaitannya dengan teknologi. Salah satu yang kami tawarkan adalah modul sederhana penggunaan program sibelius yang berfungsi untuk mengembangkan ataupun membuat materi ajar khususnya mata pelajaran seni budaya bidang musik, seperti menulis lagu menggunakan notasi balok, membuat aransemen sederhana dan lain sebagainnya. Salah satu kompetensi dasar yang harus dimiliki guru musik adalah menuliskan notasi musik untuk mempermudah proses pembelajaran musik (Sinaga, Maestro, Winangsit, \& Yensharti, 2019, p. 143).

Penelitian ini difokuskan kepada guru-guru mata pelajaran Seni Budaya tingkat SMA di Kabupaten Solok. Berdasarkan K-13 mapel Seni Budaya terdapat salah satu bab yaitu Musik Teknologi. Notasi musik digunakan dalam proses pembelajaran musik untuk memudahkan peserta didik memainkan materi lagu yang diberikan, baik menggunakan alat musik pianika, rekorder, maupun instrumen ritmis sederhana. 
Dalam wawancara dengan Risnawati, selaku ketua MGMP Seni Budaya Kabupaten Solok, sebagian besar guru mengalami kesulitan ketika harus mengajarkan bab tersebut, maka dari itu tim penulis melakukan eksperimen dengan modul sederhana untuk penggunaan software Sibelius yang dapat dimanfaatkan untuk mengembangkan maupun menyampaikan materi pada mata pelajaran Seni Budaya, khususnya dalam penulisan notasi balok dan pembuatan aransemen lagu sederhana.

\section{Metode}

Penelitian ini merupakan penelitian uji-coba modul sederhana penggunaan program sibelius yang termasuk dalam pengembangan media dalam konteks pembelajaran seni budaya di sekolah tingkat SMA. Penelitian dilaksanakan di Kabupaten Solok, Sumatera Barat dengan subjek penelitian yaitu MGMP Seni Budaya se-Kabupaten Solok. Pendekatan yang digunakan adalah pendekatan artistik "Art Practice Based Research". Hal tersebut berkaitan dengan tujuan penelitian ini yaitu membantu permasalahan yang sering terjadi dalam menyampaikan dan mengembangkan materi ajar khususnya materi yang berkaitan dengan musik teknologi seperti software sibelius.

Pendekatan artistik mencangkup pengkajian dan penciptaan seni, salah satunya adalah produk pendidikan mata pelajaran Seni Budaya dan Keterampilan K-13 seperti pengembangan metoda mengajar, pengembangan perangkat pembelajaran, dan penyampaian materi ajar (Rohidi, 2014, p. 2). Berdasarkan hal tersebut menjadikan pendekatan yang dipilih memiliki relevansi tinggi dalam penelitian berjudul software sibelius sebagai alternatif penulisan notasi musik di era millenial.

\section{Hasil dan Pembahasan}

\section{Penulisan Notasi Musik}

Permasalahan yang sering ditemukan dalam proses pembelajaran Seni Budaya dan Keterampilan adalah penulisan notasi musik menggunakan software musik, sehingga dalam menentukan materi ajar guru hanya terbatas pada bahan-bahan yang tersedia di internet. Hal tersebut memberikan efek yang kurang baik kepada siswa, salah satunya membuat siswa tidak berminat ataupun malas dalam proses pembelajaran seni musik.

Data di lapangan menunjukan bahwa tidak semua guru mapel Seni Budaya dan Keterampilan memiliki kompetensi lulusan Sarjana Musik, sehingga guru yang berasal dari luar bidang seperti tari maupun drama mengalami kesulitan dalam mengajarkan materi penulisan notasi musik yang berkaitan dengan penulisan musik teknologi. Dalam proses pelatihan hal yang paling fundamental adalah dasar-dasar teori musik yang berkaitan dengan ritmis dan melodi (Hartiningsih, 2015), selain itu guru musik harus dapat menggunakan beberapa alat musik tradisional yang ada disekitar untuk dijadikan sebagai salah satu media dalam proses pembelajaran. Salah satu manfaat yang dirasakan dalam pembelajaran musik tradisi daerah setempat adalah, peserta didik dapat lebih mengenal alat musik yang berasal dari daerah tersebut dan dapat memberikan pengalaman estetis secara tidak sadar agar dapat terus melestarikan musik tradisi daerah setempat (Maestro \& Sinaga, 2018).

Dalam penggunaan sibelius tidak selalu terdapat alat musik yang dikehendaki, namun guru dapat menggantikannya dengan alat musik yang hampir sejenis, baik dilihat pada clef yang digunakan maupun jangkauan nada yang dapat dihasilkan. 


\section{Sibelius sebagai Alternatif Penulisan Notasi Musik}

Berdasarkan riset dari (Bahaudin, 2017, p. 430) software sibelius terbukti sangat efektif untuk membantu siswa maupun guru dalam penulisan notasi musik, hal tersebut dikarenakan notasi yang dituliskan dapat langsung dibunyikan sehingga siswa lebih tertarik dan mudah memahami nilai notasi maupun pitch notasi.

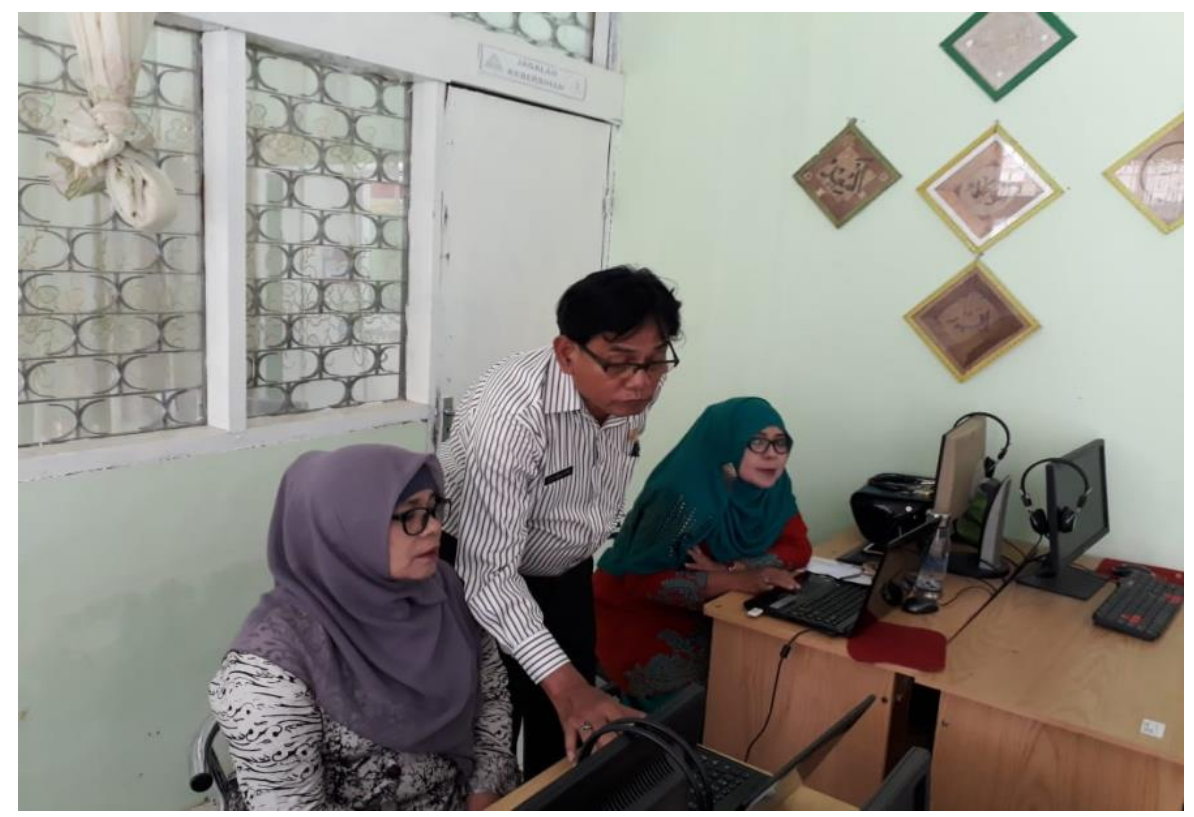

Gambar 2. Tim Peneliti memberikan arahan tentang cara instalasi software Sibelius (Sumber: Sinaga, 2018)

Pelaksanaan uji coba modul sederhana penggunaan software sibelius kepada MGMP Seni Budaya tingkat SMA Se-Kabupaten Solok memberikan efek yang sangat luar biasa. Pelatihan diberikan sebanyak tiga kali pertemuan dengan materi yang berbeda-beda. Pertemuan pertama peserta diberikan tata cara tentang instalasi software sibelius pada masing-masing laptop maupun PC. Kendala yang dihadapi pada tahap ini banyak guru yang masih belum terbiasa dengan prosedur instalasi software pada OS Windows, namun tim sudah bagikan file installer sibelius kepada peserta ditambah catatan kecil dan panduan secara langsung tentang proses instalasi.

Pertemuan kedua dengan modul sederhana penggunaan software sibelius, tim peneliti langsung mengarahkan peserta untuk memilih lagu yang akan dituliskan kedalam notasi balok menggunakan software Sibelius yang sudah terinstal pada laptop masing-masing. Risnawati selaku salah satu peserta memilih lagu berjudul "Desaku Yang Kucinta" untuk dituliskan kedalam notasi balok. Pada pertemuan kedua tim peneliti memberikan waktu hingga seminggu kedepan untuk menyelesaikan penulisan notasi musik menggunakan software sibelius. Hasil yang didapatkan setelah peserta menuliskan lagu berjudul Desaku Yang Kucinta sebagai berikut, 


\section{Desaku Yang Kucinta}

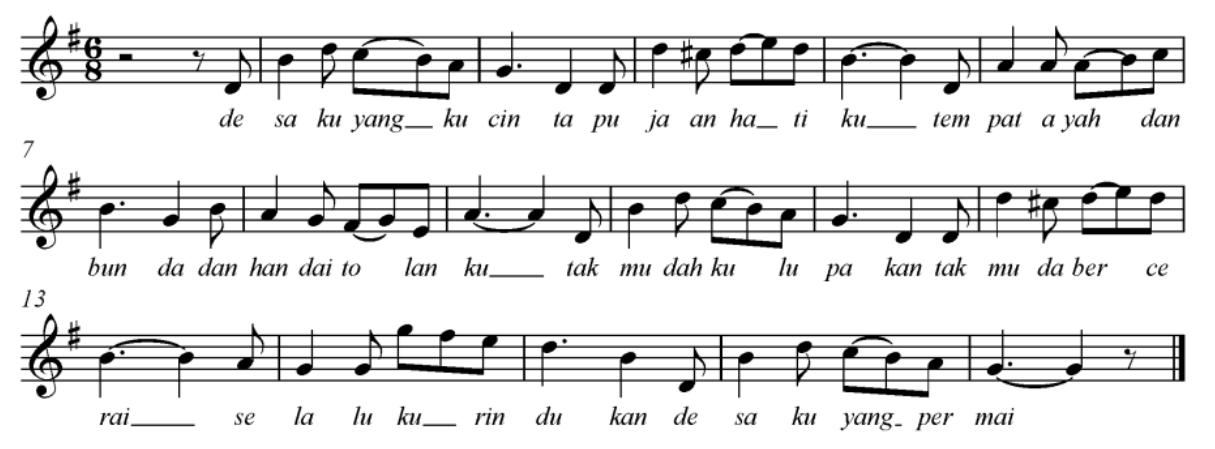

Gambar 3. Lagu berjudul Desaku Yang Kucinta

(Sumber: Risnawati)

Setelah waktu berjalan satu minggu dan hampir beberapa peserta sudah menyelesaikan transkripsi lagu yang sudah ditentukan, pada pertemuan ketiga peserta diberi pelatihan tentang proses aransemen. Menurut (Sanjaya, 2013, p. 33) aransemen dibagi menjadi lima bagian yaitu konsep aransemen, aransemen awal, penciptaan ide baru, aransemen lanjut, dan evaluasi serta revisi. Dalam pelatihan ini peserta hanya diberikan keterampilan untuk membuat dua suara dan membaginya kedalam instrumen musik sekolah seperti rekorder dan pianika. Hasil yang diperoleh setelah tiga pertemuan, guru dapat menuliskan sendiri lagu yang mereka pilih ke dalam notasi balok menggunakan software sibelius dan membuatnya menjadi dua suara pada rekorder dan pianika. Hal tersebut dapat dilihat pada notasi berikut,

Desaku Yang Kucinta

L. Malik
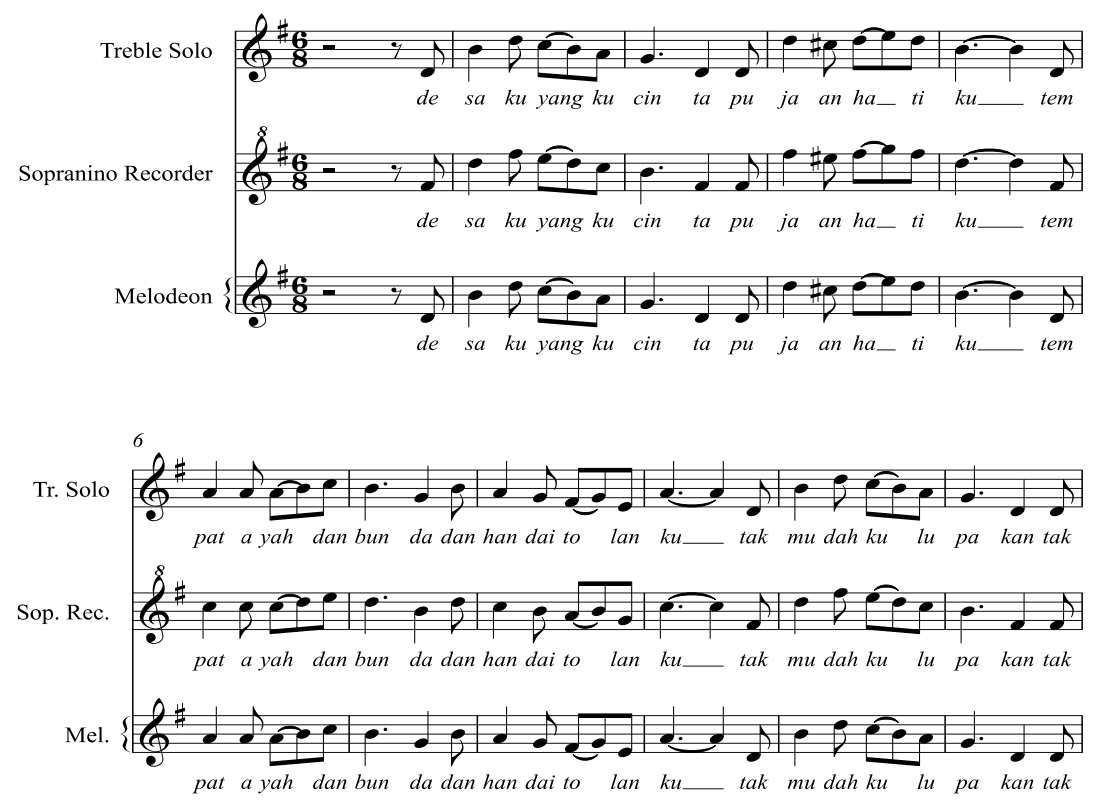

Gambar 4. Penggalan Aransemen dari Guru

(Sumber: Risnawati) 


\section{Kesimpulan}

Berdasarkan penelitian dan eksperimen yang sudah dilakukan pada peserta guru yang tergabung dalam MGMP Seni Budaya SMA Se-Kabupaten Solok dapat disimpulkan bahwa dengan software Sibelius guru dapat menjadikan software tersebut sebagai alternatif penulisan notasi musik dan aransemen secara sederhana guna keperluan penyampaian dan pengembangan materi ajar. Guru mendapatkan keterampilan tentang tata cara instalasi software Sibelius pada OS Windows sehingga mereka dapat memperbanyak software tersebut di komputer lab sekolah. Penulisan notasi musik menggunakan sibelius memberikan kemudahan karena dapat langsung dibunyikan, dan guru dapat membedakan secara mandiri jika ada notasi yang kurang tepat. Penggunaan software sibelius dalam aransemen memberikan kemudahan karena kita dapat melakukan copy-paste notasi asli ke dalam beberapa alat musik dan mengaransemen menjadi dua suara.

\section{References}

Bahaudin, I. (2017). Pembelajaran Notasi Balok Melalui Software Sibelius, 429-436.

Hartiningsih, S. (2015). Revitalisasi Lagu Dolanan Anak dalam Pembentukan Karakter Anak Usia Dini. ATAVISME. https://doi.org/10.24257/atavisme.v18i2.119.247-259

Maestro, E., \& Sinaga, F. S. S. (2018). Kearifan Lokal Lagu Ayam Den Lapeh Garapan Orkes Gumarang.

Rohidi, T. R. (2014). Pengembangan Media Pembelajaran Pendidikan Seni Budaya Berbasis Kearifan Lokal (Wayang Sebagai Sumber Gagasan). Imajinasi, VIII(1), 1-8.

S, D. (2016). Generasi Millenial dan Karakteristiknya. Retrieved October 28, 2018, from https://student.cnnindonesia.com/edukasi/20160823145217-445-153268/generasimillenial-dan-karakteristiknya/

Sanjaya, R. M. S. (2013). Metode Lima Langkah Aransemen Musik. Promusika, 1(1), 33-49.

Sinaga, F. S. S., Maestro, E., Winangsit, E., \& Yensharti, Y. (2019). Learning and Singing: Thematic Children Songs in Kindergarten. In Seventh International Conference on Languages and Arts (ICLA 2018). Padang: Atlantis Press. Retrieved from https://www.atlantis-press.com/article/55914484 